\title{
Antineoplastic effects and mechanisms of micheliolide in acute myelogenous leukemia stem cells
}

\author{
Qing $\mathrm{Ji}^{1, *}$, Ya-hui Ding ${ }^{1,2, *}$, Yue Sun ${ }^{1, *}$, Yu Zhang ${ }^{1, *}$, Hui-er Gao ${ }^{1}$, He-nan Song ${ }^{1}$, \\ Ming Yang ${ }^{1}$, Xiao-lei Liu ${ }^{1}$, Zi-xiang Zhang ${ }^{3}$, Ying-hui Li ${ }^{1}$, Ying-dai Gao ${ }^{1}$ \\ ${ }^{1}$ State Key Laboratory of Experimental Hematology, Institute of Hematology and Hospital of Blood Diseases, Chinese \\ Academy of Medical Sciences and Peking Union Medical College, Tianjin 300020, P. R. China \\ ${ }^{2}$ The State Key Laboratory of Medicinal Chemical Biology, College of Pharmacy, Nankai University, Tianjin 300071, P. R. China \\ ${ }^{3}$ Department of Stomatology, Institute of Hematology and Blood Diseases Hospital, Chinese Academy of Medical Sciences \\ and Peking Union Medical College, Tianjin 300020, P. R. China \\ *These authors contributed equally to this work
}

Correspondence to: Ying-dai Gao, email: ydgao@ihcams.ac.cn

Keywords: leukemic stem cells, micheliolide

Received: February 24, $2016 \quad$ Accepted: August 09, 2016

Published: August 17, 2016

\section{ABSTRACT}

Leukemic stem cells (LSCs) greatly contribute to the initiation, relapse, and multidrug resistance of leukemia. Current therapies targeting the cell cycle and rapidly growing leukemic cells, including conventional chemotherapy, have little effect due to the self-renewal and differentiated malignant cells replenishment ability of LSCs despite their scarce supply in the bone marrow. Micheliolide (MCL) is a natural guaianolide sesquiterpene lactone (GSL) which was discovered in michelia compressa and michelia champaca plants, and has been shown to exert selective cytotoxic effects on CD34+CD38- LSCs. In this study, we demonstrate that DMAMCL significantly prolongs the lifespan of a mouse model of human acute myelogenous leukemia (AML). Mechanistic investigations further revealed that MCL exerted its cytotoxic effects via inhibition of NF-KB expression and activity, and by generating intracellular reactive oxygen species (ROS). These results provide valuable insight into the mechanisms underlying MCL-induced cytotoxicity of LSCs, and support further preclinical investigations of MCL-related therapies for the treatment of AML.

\section{INTRODUCTION}

The presence of leukemic stem cells (LSCs) has been confirmed in several human hematological malignancies, and is considered as a key factor that contributes to the initiation, maintenance, relapse, and drug-resistance of leukemia [1,2]. Similar to normal hematopoietic stem cells (HSCs), LSCs have the capacity to self-renew and differentiate, thereby allowing them to propagate and generate additional progeny with defective development potential. Consequently, hematopoietic homeostasis is compromised and the risk of leukemia and other hematological malignancies are enhanced $[3,4]$. Conventional chemotherapy eliminates the bulk of rapidly growing, differentiated leukemic cells, yet it fails to completely eradicate the significantly smaller pool of LSCs that is often present as a relatively quiescent cell population $[5,6]$. Therefore, novel LSC-directed therapies that specifically target this rare stem cell fraction are urgently needed to combat leukemia.

LSCs exhibit similar stem-like characteristics to HSCs, although the unique features that render LSCs as a potential risk factor of hematological malignancies remain unknown. It is hypothesized that LSCs rely on cell-intrinsic signaling pathways. Several canonical developmental pathways, including the $\mathrm{Wnt} / \beta$-catenin and Hedgehog signaling pathways which are evolutionarily conserved and tightly controlled in adult tissues, play an essential role in normal stem cell function [7, 8]. Previous studies have shown that the activation of $\beta$-catenin in LSCs enhances self-renewal activity and leads to abnormal expansion and leukemic potential $[9,10]$. Additionally, the $\mathrm{PI} 3 \mathrm{~K} / \mathrm{AKT} / \mathrm{mTOR}$ pathway plays a major survival role during normal hematopoietic homeostasis, yet is frequently dysregulated in leukemia [11-13]. Currently, abnormal expression of NF- $\mathrm{kB}$ is regarded as a crucial contributor 
to leukemogenesis, and targeted therapies involving $\mathrm{NF}-\kappa \mathrm{B}$ have been designed to induce LSCs-specific apoptosis [14]. Two regulators of NF- $\kappa \mathrm{B}$ that have been implicated as tumor suppressor genes, DAPK and IRF-1, have been found to be deregulated and present in many samples obtained from patients with acute myelogenous leukemia (AML) [15]. Higher levels of reactive oxygen species have also been observed in primitive leukemic cells compared to normal lymphocytes [16, 17]. Furthermore, the adaptation of leukemic cells to oxidative stress is considered to be a significant factor in establishing a drug resistance phenotype [18]. Therefore, elucidation of the mechanistic details of the key signaling pathways that modulate LSC proliferation and self-renewal will be increasingly critical not only for the generation of LSC-targeted therapies, but also for a better understanding of the pathological mechanisms underlying disease initiation and progression.

Small molecules offer great advantages for the research and treatment of leukemia due to their rapid and diverse effects on many different cell types. Several small molecules, such as parthenolide (PTL), impart specific cell-killing effects on LSCs. For example, inhibition of NF-кB and production of reactive oxygen species (ROS) appear to be essential for PTL-mediated activity against CD $34^{+} \mathrm{CD}^{-} 8^{-}$LSCs $[19,20]$. However, the instability of PTL under acidic and basic conditions limits its application as a molecular probe in vivo or as a therapeutic reagent [21]. We previously characterized micheliolide (MCL), a natural guaianolide sesquiterpene lactone (GSL) from Michelia compressa and Michelia champaca plants [22]. We also synthesized MCL from PTL [22]. MCL was found to selectively eradicate AML stem/progenitor cells (e.g., CD34 ${ }^{+} \mathrm{CD} 38^{-}$cells). MCL and its water-soluble Michael adduct, DMAMCL, have exhibited strong antiinflammatory properties [23]. Furthermore, DMAMCL displayed higher plasma stability, a more sustained release, and superior in vivo efficacy compared to DMAPTL [24]. The goal of this study was to characterize the potential for MCL to serve as an LSC-targeted therapy. Therefore, the effects of MCL on different hematopoietic cell populations from patients with AML, and also in a humanized mouse model of leukemia, were investigated. Furthermore, we sought to elucidate the mechanisms by which MCL functions to selectively induce apoptosis in LSCs.

\section{RESULTS}

\section{MCL inhibits cell proliferation and selectively induces apoptosis in leukemic stem/progenitor cells (LSPCs)}

We previously demonstrated that MCL inhibits leukemia cell proliferation. Accumulating data suggest that cells that hyper-express of multi-drug resistance related genes show the phenotype CD34+ in human hematopoietic stem cells. It has been reported that multidrug resistance related genes may be involved in the regulation of key processes of stem cells [25]. Therefore, we first assessed whether MCL could also inhibit the proliferation of drug-resistant leukemic cell lines. Meanwhile, KG1a cells exhibit an LSC-like phenotype with high levels of CD34 expression (98.6\%) and low levels of CD38 expression (24.6\%), so it was considered as a leukemia stem-like cell line. When drug-resistant cell lines were treated with MCL, significant cytotoxicity was induced in leukemia multi-drug resistant cells (Table 1). In particular, increasing concentrations of MCL induced apoptosis in KG1a cells (Figure 1A and 1C) and primary AML cell (Figure 1B) in a dose-dependent manner. In a time course assay, high levels of apoptosis were detected $2 \mathrm{~h}$ after MCL treatment. The level of apoptosis further increased after $4 \mathrm{~h}$, and then remained constant up to $24 \mathrm{~h}$ later in KG1a cell line (Figure 1D). Thus, MCL induced significant cytotoxicity in multidrug-resistant leukemic cells for at least $24 \mathrm{~h}$.

Twenty primary AML specimens were subsequently selected to investigate the effects of MCL on different hematopoietic cell populations. CD34 ${ }^{+}$LSPCs and total mononuclear cells (MNCs) were sorted and isolated from tissue samples. Treatment of the LSPCs with MCL induced greater cytotoxicity compared to the treatment of total MNCs (Table 2 and Figure 1E). In contrast, MCL treatment did not induce significant cytotoxic effects in the hematopoietic stem and progenitor cells (HSPCs) obtained from human umbilical cord blood (Figure 1F).

To further characterize the effects of MCL on leukemic cells, methylcellulose colony-forming unit (CFU) assays were performed. The number of colonies was significantly reduced in response to MCL treatment compared to untreated controls (Figure 1G). Notably, cells isolated from AML1, AML4, and AML10 tissue specimens failed to form any colonies after treatment with MCL (Table 3). Conversely, MCL treatment of HSPCs obtained from human umbilical cord blood had no effect on colony formation, independent of MCL concentration (Figure 1H). Taken together, these data suggest that MCL specifically inhibits malignant hematopoiesis of LSPCs, and not normal hematopoiesis.

\section{MCL improves survival in a mouse model of human AML}

The finding that MCL eliminated LSPCs in vitro led us to further analyze the effect of MCL in an in vivo system. A NOD/SCID xenotransplantation leukemia model was established following irradiation (250 cGy) and an injection of primary human AML MNCs $\left(1 \times 10^{7}\right)$. CD $45^{+}$cells were detected in the bone marrow 8 weeks later, indicating that a successful engraftment had occurred to generate AML mice. The pro-drug form of MCL, DMAMCL, was 
Table 1: Cytotoxicity of multidrug-resistant cell lines exposed to MCL or ADR

\begin{tabular}{|c|c|c|}
\hline Cell Line & MCL $(\mathrm{SD} \pm \mathrm{SEM}, \mu \mathrm{M})$ & $\mathrm{ADR}(\mathrm{SD} \pm \mathrm{SEM}, \boldsymbol{\mu M})$ \\
\hline HL60 & $4.30 \pm 0.02$ & $0.0165 \pm 0.0078$ \\
\hline HL60/ADR & $6.25 \pm 1.06$ & $4.85 \pm 1.06$ \\
\hline K562 & $7.85 \pm 1.48$ & $0.06 \pm 0.01$ \\
\hline K562/A02 & $8.15 \pm 0.49$ & $8.55 \pm 2.19$ \\
\hline K526/G & $5.15 \pm 0.49$ & $0.028 \pm 0.011$ \\
\hline KG1a & $9.40 \pm 0.28$ & $0.72 \pm 0.34$ \\
\hline
\end{tabular}

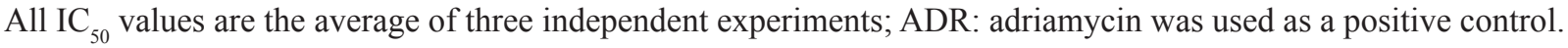

orally administered to these AML mice at doses of $25 \mathrm{mg} /$ $\mathrm{kg}, 50 \mathrm{mg} / \mathrm{kg}$, and $100 \mathrm{mg} / \mathrm{kg}$ for a total of 7 treatments every other day. As a positive control, ADR, a traditional chemotherapy drug, was injected via the tail vein at a dose of $2 \mathrm{mg} / \mathrm{kg}$ for a total of 4 treatments every two days.

The average lifespan of the AML model was markedly increased compared to the control group which was injected with PBS (Figure 2A). $\mathrm{CD}^{+} 5^{+}$cell engraftment was then determined by flow cytometry (Figure 2B). A greater number of mice with lower level of engraftment $(<5 \%)$ were observed after DMAMCL treatment (Figure 2C). Meanwhile, the number of mice exhibiting engraftment levels at $5-10 \%$ and $10-50 \%$ after DMAMCL treatment was reduced (Figure 2C). Collectively, these results suggest that MCL treatment improved the survival of the human AML mouse model.

\section{Transcriptome analysis of MCL-treated leukemic cells reveals differential expression of genes associated with ROS and NF- $\mathrm{NB}$ signaling}

To analyze the molecular mechanisms by which MCL induced apoptosis, microarray gene expression profiling of MCL-treated KGla cells was performed. KG1a cells exhibit an LSC-like phenotype with high levels of CD34 expression (98.6\%) and low levels of CD38 expression (24.6\%). After MCL treatment, the expression of apoptosis-related genes was found to be altered at least two-fold (Figure 3A). In particular, several anti-apoptosis-related genes were down regulated, including API5, FGFR2, TNFSF14, TFRC, XIAP, BIRC3, and PLAC8 compared to control (Figure 3B). Conversely, pro-apoptosis-associated genes, including RIPK1,

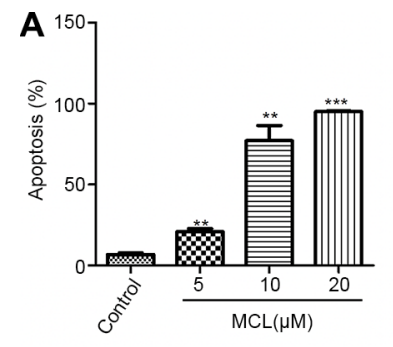

E

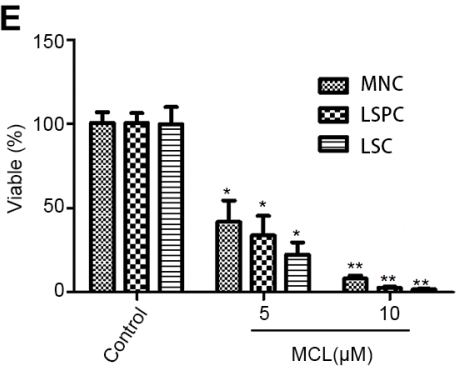

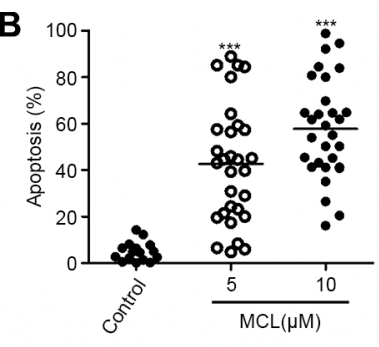

$\mathbf{F}$

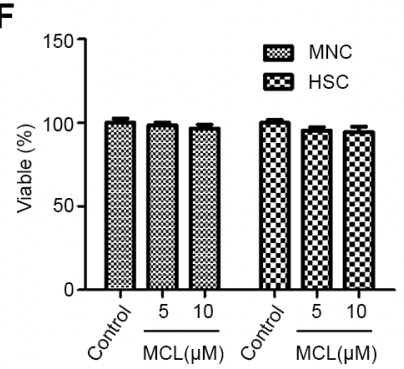

C

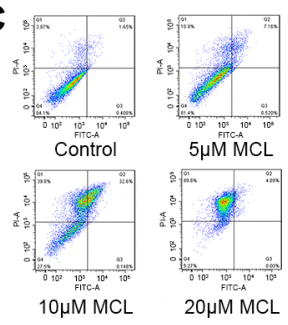

G

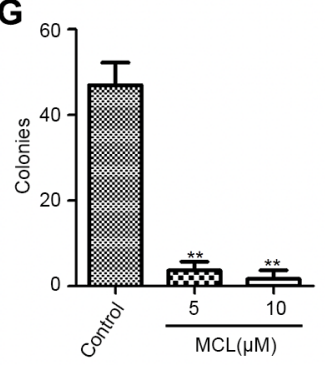

D

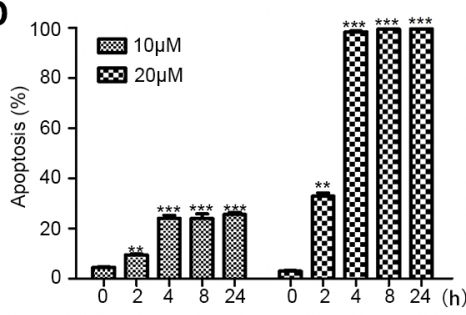

H

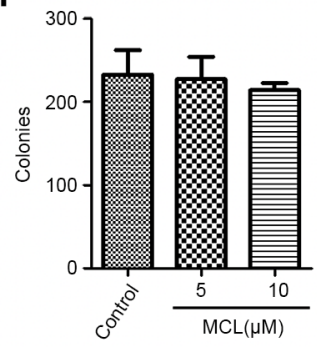

Figure 1: MCL selectively induces the apoptosis of AML leukemic stem cells, but not normal hematopoietic stem cells. (A) Percentage of apoptosis was assessed in KGla cells treated with MCL. Control represents untreated cells. (B) Percentage of apoptosis was assessed in cells isolated from primary AML specimens $(n=20)$ and treated with MCL. (C) Representative flow cytometry scatter plots displaying apoptotic cell populations after treatment with MCL. (D) Percentage of apoptosis was assessed in KGla cells treated with MCL at different time points over $24 \mathrm{~h}$. (E) Percentage of viability was assessed in MNCs, LSCs (CD34 ), and LSPCs (CD34 $4^{+}$CD38-) isolated from AML specimens and treated with MCL. (F) Percentage of apoptosis was assessed in MNCs and HSCs (CD34 $\left.{ }^{+} \mathrm{CD} 38^{-}\right)$isolated from human umbilical cord blood and treated with MCL. (G) Colony-forming abilities of MNCs isolated from primary AML specimens and treated with MCL. (H). Colony-forming abilities of HSCs isolated from human umbilical cord blood and treated with MCL. Control represents untreated cells. Error bars represents the SEM. ${ }^{* *} P<0.001 ; * * P<0.01 ; * P<0.05$; ns, no significance. 
Table 2: Viability of primary AML cells treated with MCL

\begin{tabular}{|c|c|c|c|c|c|}
\hline \multirow{2}{*}{ AML Sample } & \multirow{2}{*}{ subtype } & \multicolumn{2}{c}{ Total Cells (\% viable) } & \multicolumn{2}{c}{ LSPCs (\% viable) } \\
\cline { 3 - 6 } & & $\mathbf{5} \boldsymbol{\mu M}$ MCL & $\mathbf{1 0} \boldsymbol{\mu M}$ MCL & $\mathbf{5} \boldsymbol{\mu M}$ MCL & $\mathbf{1 0} \boldsymbol{\mu M}$ MCL \\
\hline AML1 & M3 & 88.0 & 80.0 & 56.5 & 53.4 \\
\hline AML2 & M6 & 70.1 & 47.3 & 88.2 & 73.9 \\
\hline AML3 & CML-AP & 78.0 & 59.0 & 65.7 & 23.5 \\
\hline AML4 & M4 & 17.4 & 15.4 & 11.0 & 9.0 \\
\hline AML5 & M5 & 45.3 & 27.7 & 34.7 & 23.9 \\
\hline AML6 & M2 & 93.7 & 78.7 & 95.3 & 74.2 \\
\hline AML7 & N/A & 73.3 & 58.2 & 65.9 & 53.7 \\
\hline AML8 & N/A & 79.8 & 61.9 & 65.7 & 31.2 \\
\hline AML9 & M3 & 29.1 & 11.9 & 14.5 & 3.7 \\
\hline AML10 & M1 & 48.9 & 35.1 & 38.7 & 11.5 \\
\hline AML11 & M4 & 67.2 & 42.1 & 23.0 & 21.2 \\
\hline AML12 & M2 & 42.2 & 36.7 & 23.8 & 13.4 \\
\hline AML13 & M4 & 11.9 & 3.2 & 10.0 & 1.1 \\
\hline AML14 & M3 & 56.0 & 54.6 & 50.3 & 35.2 \\
\hline AML15 & M2 & 89.0 & 42.1 & 93.0 & 45.3 \\
\hline AML16 & M3 & 77.1 & 58.0 & 56.5 & 31.3 \\
\hline AML17 & M5 & 58.0 & 43.5 & 55.7 & 46.0 \\
\hline AML18 & M4 & 34.1 & 8.9 & 29.0 & 2.8 \\
\hline AML19 & M5 & 28.7 & 18.7 & 34.7 & 21.6 \\
\hline AML20 & M5 & 49.9 & 35.0 & 23.6 & 16.3 \\
\hline AMnyyyyy & & & & & \\
\hline
\end{tabular}

All values were carried out as triplicated. And the percentage of viable was compared as its control.

Table 3: Colony formation of primary AML cells treated with MCL

\begin{tabular}{|c|c|c|c|}
\hline \multirow{2}{*}{ AML Sample } & \multicolumn{3}{|c|}{ Number of colonies $(\mathrm{SD} \pm \mathrm{SEM}, \mu \mathrm{M})$} \\
\hline & Control & $5 \mu \mathrm{M}$ MCL & $10 \mu \mathrm{M} M C L$ \\
\hline AML1 & $36.0 \pm 8.5$ & 0 & 0 \\
\hline AML2 & $50.0 \pm 5.2$ & $2.7 \pm 1.5$ & $0.3 \pm 0.6$ \\
\hline AML3 & $47 \pm 5.3$ & $3.7 \pm 2.1$ & $1.7 \pm 2.1$ \\
\hline AML4 & $10.0 \pm 2.6$ & $3.7 \pm 1.5$ & 0 \\
\hline AML6 & $222.0 \pm 41.0$ & $158.0 \pm 24.0$ & $2.3 \pm 4.0$ \\
\hline AML7 & $45.0 \pm 13.7$ & $37.0 \pm 4.2$ & $4.7 \pm 4.2$ \\
\hline AML8 & $114.3 \pm 20.5$ & $44.7 \pm 16.9$ & $7.0 \pm 6.0$ \\
\hline AML10 & $26.0 \pm 2.8$ & 0 & 0 \\
\hline
\end{tabular}

All values were carried out as triplicated. And each test was tested for three times. 
Bcl2, APAF1, PI3KR5, CASP9, and PPP $3 C C$, were up regulated compared to untreated cells (Figure $3 \mathrm{C}$ ). To further verify the transcript profiling results, a Western blot analysis of KG1a cells and primary AML specimens was performed. Levels of the apoptosis-related protein, Bax, and phosphorylated p53 both increased, while levels of the anti-apoptosis proteins, Bcl-2 and XIAP, were significantly decreased (Figure 3F). Treatment with MCL also induced increased cleavage of caspase-3, caspase-9, and PARP, all of which are proteins that have been found to be associated with active apoptosis (Figure 3F).

$\mathrm{NF}-\mathrm{\kappa B}$ signaling and intracellular levels of ROS can vary between HSPCs and LSPCs. Therefore, the genes associated with these signaling pathways were analyzed. NF-אB-related targets, including ILIRI, AGFGI, IRAK1, $N F-\kappa B 1$, and $N F-\kappa B 1 A$ were found to be differentially expressed upon MCL treatment (Figure 3D). Additionally, the expression of genes related to ROS production and oxidative responses, including GSR GCLM, HMOX1, SQSTM1, SLC7A11, EPHX1, DDIT3, PTGS2, were up regulated (Figure $3 \mathrm{E}$ ). Taken together, these data suggest that MCL may contribute to apoptosis through the NF- $\mathrm{KB}$ and ROS pathways.

\section{MCL inhibits NF-кB activity}

We next examined whether MCL exerts a direct effect on $N F-\kappa B$ expression. When primary AML MNCs were compared with normal MNCs obtained from umbilical cord blood, two-fold higher levels of $N F-\kappa B$ were detected (Figure 4A). In addition, a significant 15 -fold increase in $N F-\kappa B$ expression was detected in LSPCs compared to MNCs isolated from the same AML specimens (Figure 4C). Conversely, $N F-\kappa B$ expression was significantly reduced in normal HSPCs compared to normal $\mathrm{MNCs}$ isolated from umbilical cord blood (Figure 4B; 10-fold). A change in $N F-\kappa B$ levels was not observed within $2 \mathrm{~h}$ of MCL treatment in KGla cells, yet these levels were markedly reduced after $6 \mathrm{~h}$ of treatment (Figure 4D). Taken together, these findings suggested that $N F-\kappa B$ is selectively induced in LSCs, yet is significantly suppressed in response to MCL treatment. Thus, down regulation of NF- $\mathrm{KB}$ signaling may be required for MCL-induced apoptosis.

To further elucidate how MCL regulates NF- $\mathrm{KB}$ activity and function, cellular localization of NF- $\kappa B$ was examined in mice treated with DMAMCL. Within $3 \mathrm{~h}$ treatment, the NF- $\mathrm{KB}$ P65 subunit was observed to localize to the cytoplasm (Figure 4E). To investigate the effects of MCL treatment on the DNA-binding ability of NF- $\mathrm{KB}$, electrophoretic mobility shift assay (EMSA) assays were performed. NF- $\kappa \mathrm{B}$ binding to DNA was not significantly affected within $2 \mathrm{~h}$ of MCL treatment, yet binding of $\mathrm{NF}-\mathrm{\kappa B}$ to DNA was not detected after $8 \mathrm{~h}$ of MCL treatment (Figure $4 \mathrm{~F}$ ). When quantitative densitometry of the gel shifts was performed, MCL treatment was found to reduce the DNA binding ability of NF- $\mathrm{KB}$ in a timedependent manner (Figure 4G). We further analyzed the expression of NF- $\kappa B$ in these specimens (Figure $4 \mathrm{H}$ ), MCL exhibited better cytotoxicity in specimens with higher NF- $\mathrm{kB}$ expression. Collectively, these results provide supporting evidence that MCL-induced apoptosis may be mediated by inhibition of NF- $\mathrm{kB}$ expression and activity.

\section{Generation of intracellular ROS mediates MCL- induced apoptosis}

The reactive oxidative state of MCL-treated AML cells was examined to determine if MCL-induced apoptosis is facilitated by increased generation of intracellular ROS. A flow cytometry analysis of primary AML MNCs and LSPCs indicated that peroxides were generated within $30 \mathrm{~min}$ of MCL treatment, and the levels continued to increase in a time- and dose-dependent manner (Figure 5A and 5B). In contrast, co-treatment of cells with MCL and the glutathione precursor, $\mathrm{N}$-acetyl cysteine (NAC), prevented ROS production in primary AML MNCs (Figure 5C). Furthermore, pretreatment of LSPCs with NAC abrogated MCL-induced apoptosis (Figure 5D). A subsequent analysis of oxidative stress response mechanisms showed that $\mathrm{HO}-1$ gene expression increased approximately 8 -fold after $2 \mathrm{~h}$ of MCL treatment in AML sample compared to untreated cells, and a 30 -fold increase was detected after $6 \mathrm{~h}$ of treatment (Figure 5E). Accordingly, HO-1 protein levels significantly increased within $6 \mathrm{~h}$ of MCL treatment (Figure 5F), and immunofluorescence experiments further confirmed that expression of HO-1 and Nrf-2 both increased within $6 \mathrm{~h}$ of MCL treatment (Figure 5G). In combination, these results indicate that MCL exerts an apoptotic effect by increasing cellular oxidative stress. Many studies have shown that ROS mediated NF- $\kappa B$ cell signal pathway. To further analyze the relationship between ROS and NF- $\kappa B$, a rescue experiment was conducted. As Figure $5 \mathrm{H}$ showed, the expression of $\mathrm{p} 65$ was reduced in response to MCL treatment. Nevertheless, co-treatment of cells with MCL and N-acetyl cysteine (NAC), an inhibitor of ROS, rescued the expression of $\mathrm{p} 65$. This result suggested that ROS could inhibit the expression of NF- $\mathrm{KB}$ to some extent. Furthermore, we summarized the mechanism of MCL. As shown in Figure 5I, MCL could induce cell apoptosis directly through the accumulation of ROS, while the accumulation of ROS could inhibit the activity of NF- $\kappa B$.

\section{DISCUSSION}

The presence of small populations of LSPCs that could replenish the malignant cell pool is proposed to be a leading reason for treatment failure and leukemia relapse $[26,27]$. LSPCs also play an important role in driving chemo-resistance in patients [26]. Significant contributions by LSPCs are increasingly being realized, and efforts have 

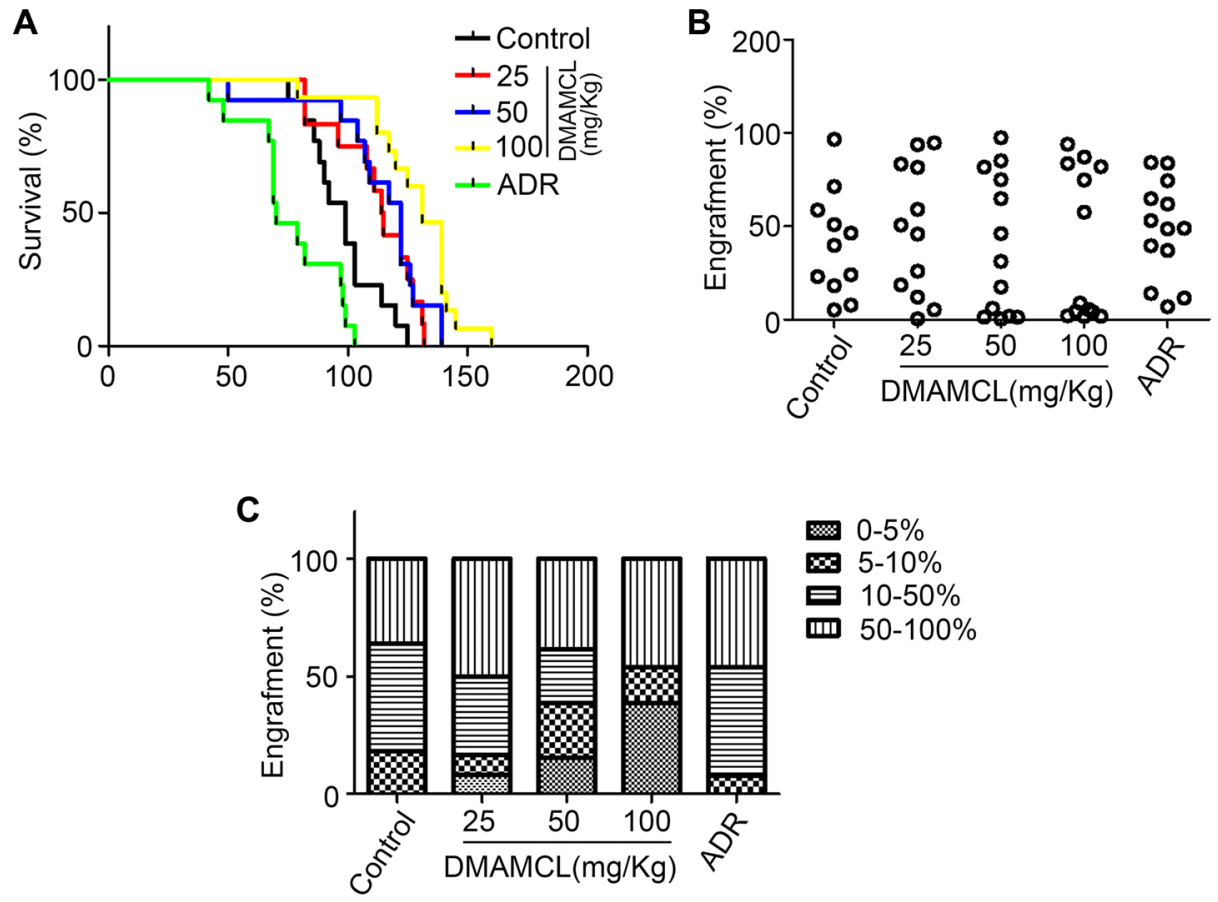

Figure 2: MCL improves the survival of mice with human AML. (A) Survival plot representing the percentage of surviving NOD/SCID mice injected with human AML cells and treated with varying doses of DMAMCL. (B) Percentage of CD45 $5^{+}$cell engraftment in the bone marrow of mice after treatment with control, DMAMCL, or ADR. (C) Percentage of mice exhibiting varying degrees of leukemic cell engraftment after treatment with control, DMAMCL, or ADR. Administration of PBS is represented by Control and ADR was administered as a positive control.

A

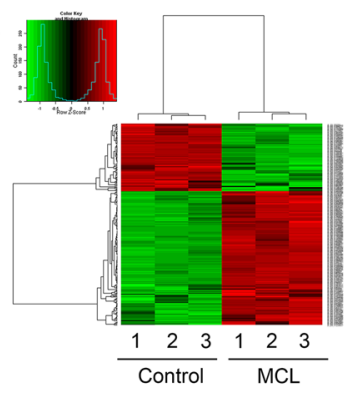

D

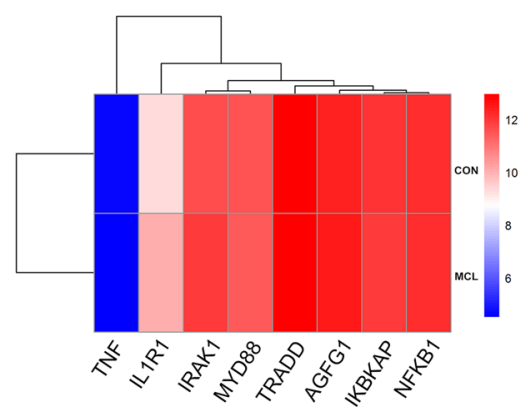

B

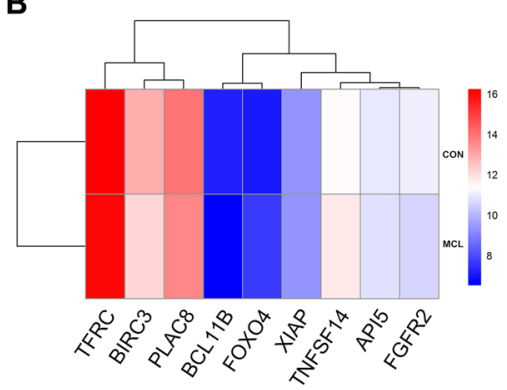

$\mathbf{E}$

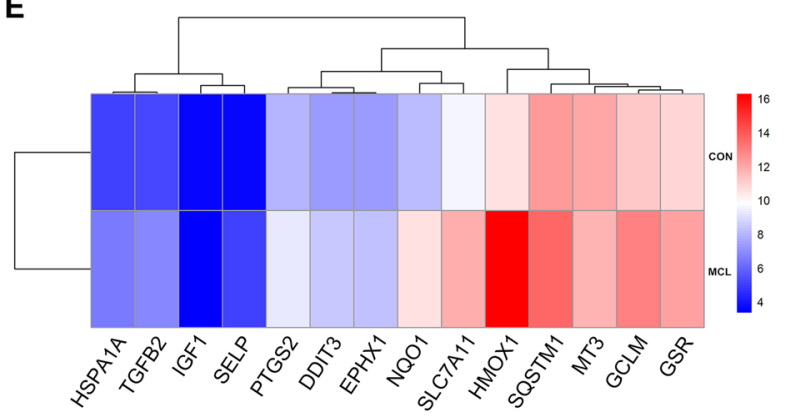

C

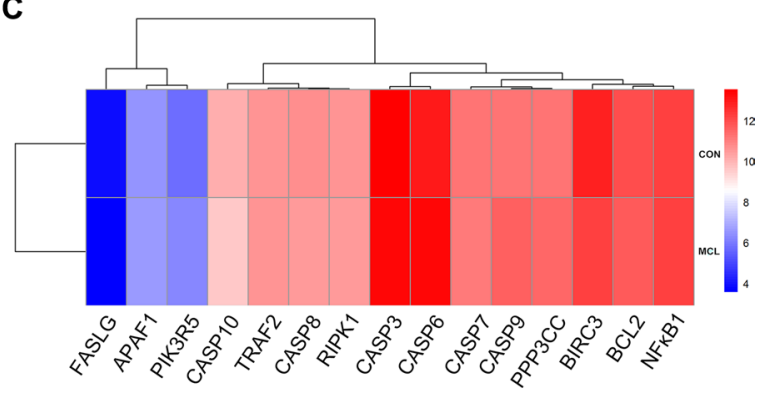

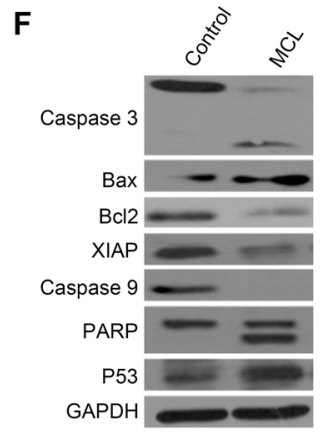

Figure 3: Transcriptome analysis of MCL-treated cells. (A) Heat map analysis of microarray data showing hierarchical clustering of differentially expressed genes between untreated and MCL-treated KG1a cells. Three independent untreated and MCL-treated cell lines were analyzed. (B) Heat map demonstrating the differences in the anti-apoptotic transcriptional signature between control and MCL-treated cells. (C) Heat map demonstrating the differences in the pro-apoptotic transcriptional signature between control and MCL-treated cells. (D) Heap map demonstrating the differences in the NF- $\mathrm{BB}$ transcriptional signature between control and MCL-treated cells. (E) Heap map demonstrating the differences in the ROS transcriptional signature between control and MCL-treated cells. (F) Western blot analysis of apoptosis-associated proteins in Control and MCL-treated KG1a cells. GAPDH was used as a loading control. 
been made to therapeutically target this stem cell niche as a strategy for the treatment of leukemia [7].

In our previous studies, we found that MCL was selectively cytotoxic to primary AML LSPCs, and detected the conversion of the pro-drug DMAMCL to MCL in plasma [24]. Therefore, in the present study, the effects of MCL on LSPCs in vivo were examined. MCL was found to exert selective and potent cytotoxic effects on LSPCs from primary AML samples, yet did not significantly affect normal MNCs and HSPCs. Furthermore, MCL was found to inhibit the capacity of LSPCs to form colonies, suggesting that MCL mediates a cytotoxic effect on LSPCs. After the treatment of AML sample with MCL for $18 \mathrm{~h}$ in vitro, a significant reduction in the engraftment of NOD/SCID mice was observed. The results from our NOD/SCID mouse model assays also demonstrated that various concentrations of MCL led to a significant increase in survival compared with ADR treatments. Collectively, our findings indicate that MCL could exert a strong cytotoxic effect on LSPCs, and MCL may represent a promising drug candidate for the treatment of leukemia.

Based on our transcriptome profiling of MCL-treated KG1a cells, the mechanisms by which MCL selectively targets LSPCs appear to be associated with activation of ROS and NF- $\kappa \mathrm{B}$ signaling. LSPCs require a hypoxic environment for survival, and an increase in intracellular ROS can lead to DNA damage and the activation of apoptotic pathways. In the present study, we found that intracellular ROS in primary AML cells markedly increased within just 30 min of MCL treatment, and this effect was both time- and dose-dependent. We also found that the level of ROS was increased when LSPCs were treated with MCL, while ROS-induced apoptosis of LSPCs could be prevented with NAC pretreatment. The expression of HO-1, which is closely related to levels of intracellular ROS, was also up-regulated in response to MCL treatment and treatment with DMAMCL, with the latter accompanied by increased Nrf-2 as well. Both HO-1 and Nrf-2 are important transcription factors that regulate the production of ROS.

In addition to inducing intracellular ROS production, MCL was also found to inhibit NF- $\kappa \mathrm{B}$ activity. NF- $\kappa \mathrm{B}$ plays a key role in the survival of LSPCs. Expression of $N F-\kappa B$ in HSPCs was low, while could be significantly induced in LSPCs. Therefore, the expression and activity status of NF- $\mathrm{\kappa B}$ may represent distinguishing features of LSPCs compared with HSPCs, and NF- $\kappa \mathrm{B}$ may serve as a potential therapeutic target for the selective elimination

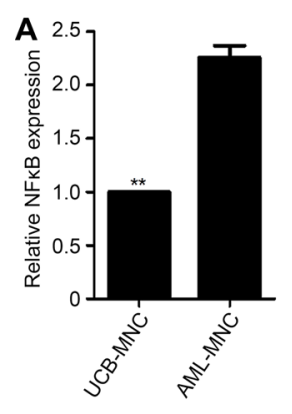

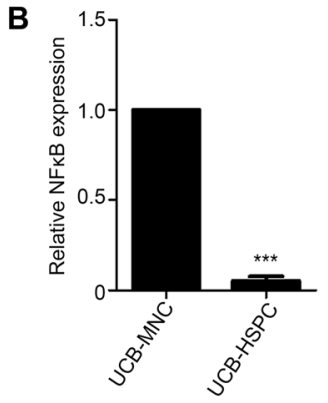
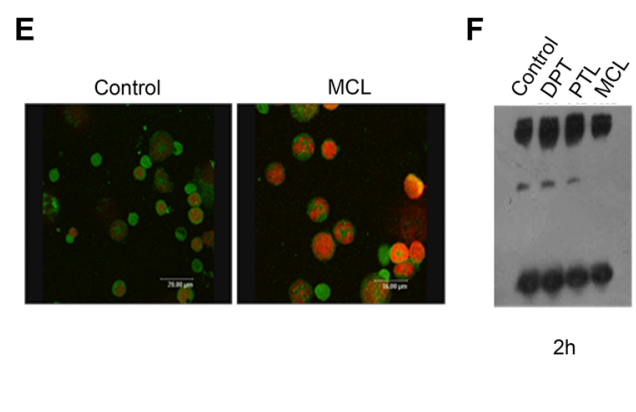

$2 \mathrm{~h}$

G

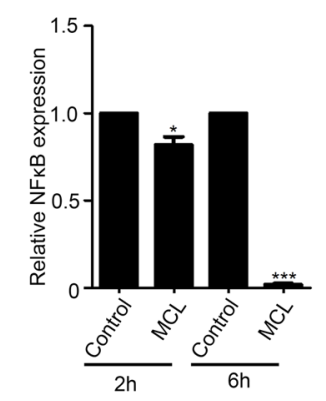

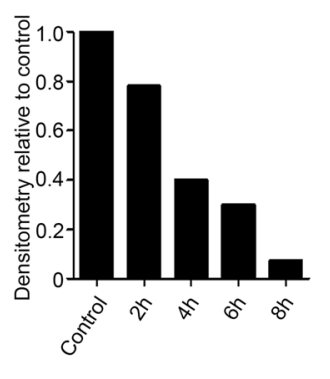

H

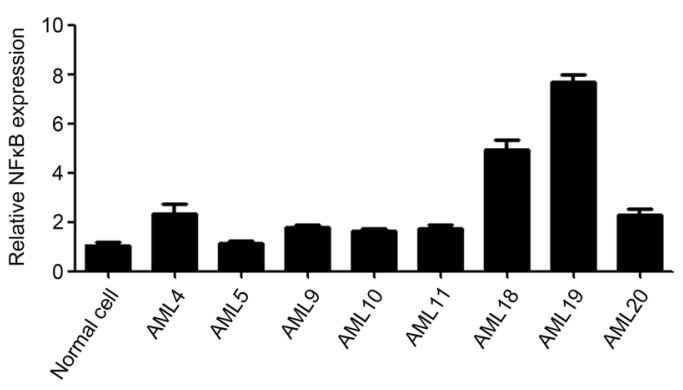

Figure 4: MCL inhibits NF-кB expression and activity in leukemic cells. (A) Relative NF- $\kappa B$ expression in mononuclear cells isolated from human umbilical cord blood or primary AML specimens. Expression was normalized to GAPDH.(b) Relative NF- $\kappa B$ expression in mononuclear and HSPCs isolated from human umbilical cord blood. Expression was normalized to GAPDH. (B) Relative NF- $\mathrm{kB}$ expression in HSPCs isolated from umbilical cord blood and LSPCs isolated from primary AML specimens. Expression was normalized to GAPDH. (C) Relative NF- $\mathrm{BB}$ expression in AMI sample treated with $10 \mu \mathrm{M}$ MCL after $2 \mathrm{~h}$ and $6 \mathrm{~h}$. Control represents untreated cells. Expression was normalized to GAPDH. (D) Immunofluorescence assays detected cellular localization of NF- $\mathrm{B}$ in bone marrow cells isolated from the AML mouse. The P65 subunit is shown in green and the nuclei are shown in red. (E) EMSA assay exhibiting NF- $\kappa B$ binding to DNA at various time points after primary AML cells were treated with $10 \mu \mathrm{M}$ MCL. Control represents untreated cells. (F) Quantitative densitometry of gel shifts from (f) relative to control cells. (G) MNCs-mononuclear cells, UCB-umbilical cord blood, HSPCs-hematopoietic stem/progenitor cells, and LSPCs-leukemic stem/progenitor cells. (H) The gene expression of NF-кB in AML specimens compared to normal cells. 

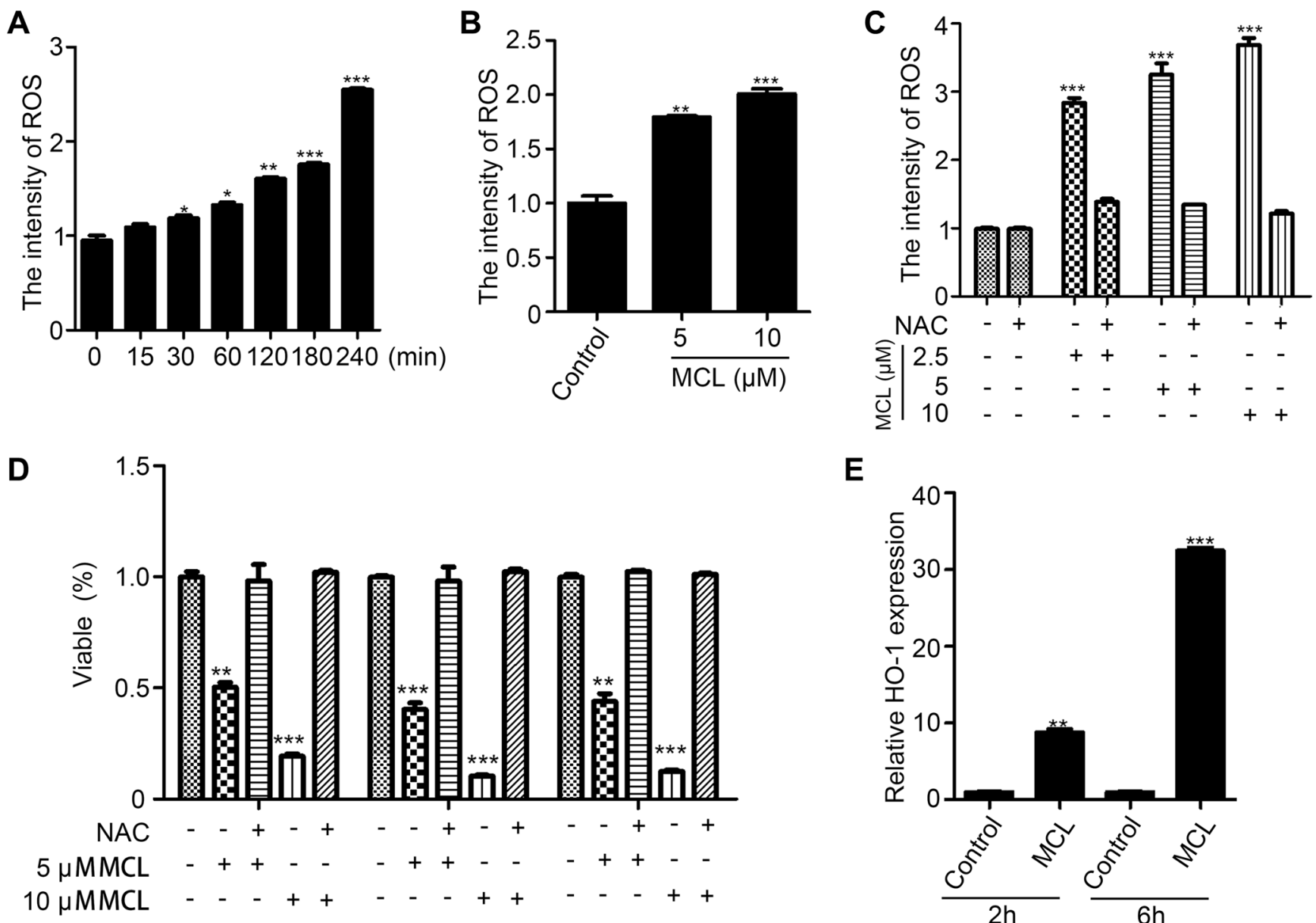

$\mathbf{E}$
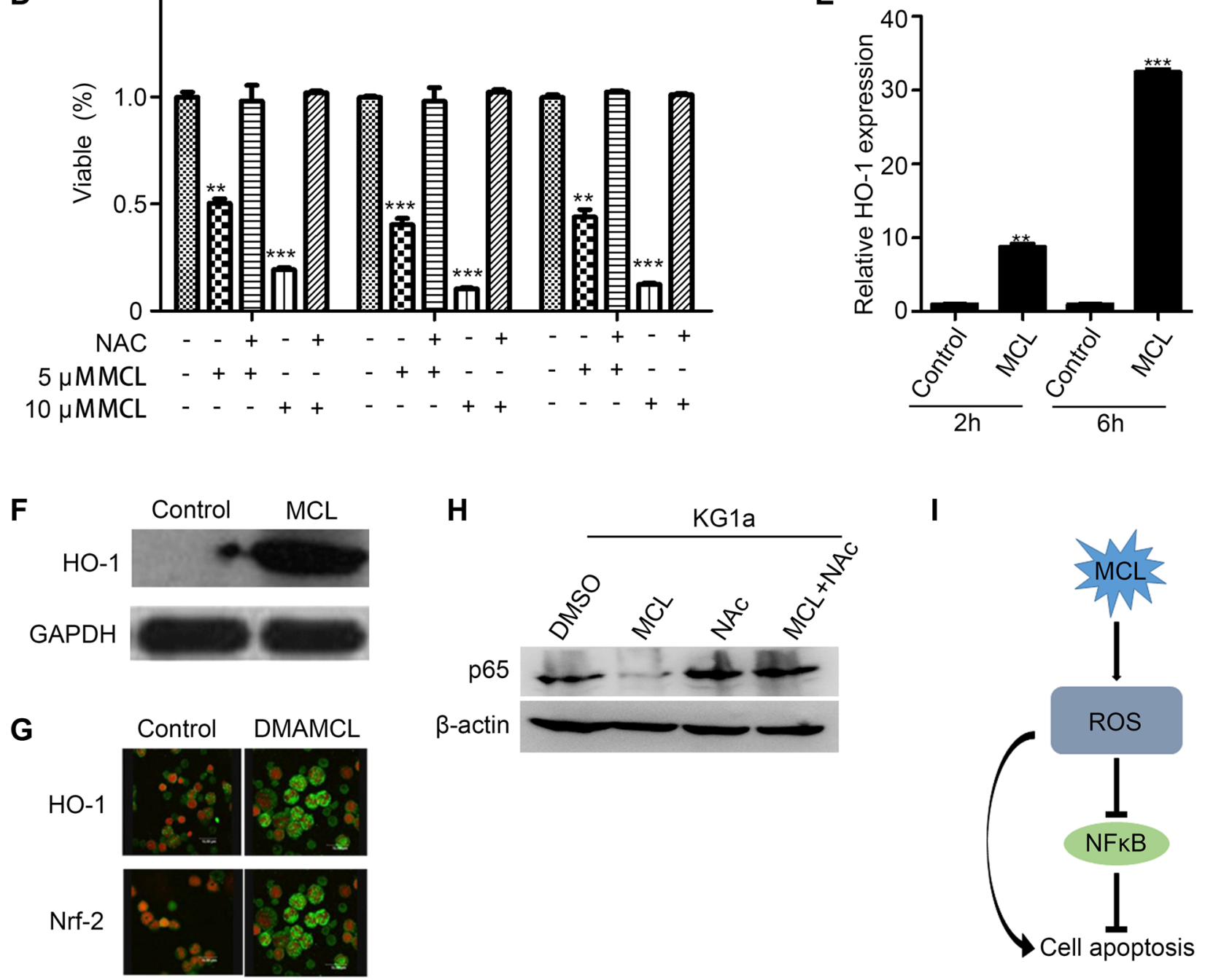

Figure 5: Generation of intracellular ROS promotes MCL-induced apoptosis. (A) ROS levels in primary AML cells treated with $10 \mu \mathrm{M}$ MCL at various time points over 240 min as measured by DCF-DA fluorescence. (B) ROS levels in primary CD34 ${ }^{+}$LSPCs treated with MCL for $1 \mathrm{~h}$. (C) ROS levels in primary AML cells co-treated with MCL and NAC. (D) Percentage of viable LSPCs pretreated with NAC and then exposed to MCL. (E) Relative HO-1 expression in primary AML cells treated with $10 \mu \mathrm{M}$ MCL after $2 \mathrm{~h}$ and $6 \mathrm{~h}$. Control represents untreated cells. Expression was normalized to GAPDH. (F) Western blot analysis of HO-1 protein expression in primary AML cells treated with $10 \mu \mathrm{M}$ MCL for $6 \mathrm{~h}$. GAPDH was used as a loading control. (G) Immunofluorescence assays that show cellular localization of HO-1 and Nrf2 in bone marrow cells isolated from AML mice. HO-1/Nrf2 proteins are shown in green and nuclei are shown in red. (H) Western blot analysis of p65 protein expression with or without ROS inhibitor NAC. (I) Mechanism of MCL in inducing cell apoptosis was summarized. 
of LSPCs. As previously reported, PTL [19], DMAPT [20], fenretinide [28], and niclosamide [29] also induce

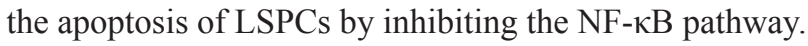
However, inhibition of NF- $\kappa$ B itself was not sufficient to induce robust apoptosis [30]. Nonetheless, in-activation of NF- $\kappa \mathrm{B}$ may sensitize primary AML cells to increased intracellular levels of ROS and enhanced apoptosis [19].

A mutual interaction between ROS and NF- $\kappa B$ exists. ROS may negatively regulate $\mathrm{NF}-\kappa \mathrm{B}$ signaling above a certain threshold and was found to have an inhibitory effect on NF- $\kappa \mathrm{B}$ activity [31-33]. Previous study has shown that ROS also mediated the role of NF- $\kappa$ B signal pathway in cells [34]. Our results proved that MCL may inhibit the NF- $\kappa \mathrm{B}$ signaling activity by promote the accumulation of intracellular ROS. Meanwhile, this result provided some evidences that the accumulation of ROS activated NF- $\mathrm{NB}$ pathway.

In conclusion, the present findings demonstrate that MCL has the capacity to eliminate LSPCs, while with no substantial effects on normal HSPCs. Consequently, MCL was considerably effective at alleviating leukemic cell engraftment in the human AML mouse model. Mechanistically, the effects of MCL appear to be mediated by inhibition of NF- $\mathrm{BB}$ and increased ROS production. Therefore, further investigations into application of MCL for clinical treatment of AML are needed. Detailed mechanisms underlying MCL function and compound optimization should also be explored in future studies.

\section{MATERIALS AND METHODS}

\section{Cell isolation, culture, and MCL compound synthesis}

Primary human AML samples were obtained from volunteer donors at the Institute of Hematology \& Blood Diseases Hospital. Human cord blood samples were obtained from volunteer donors at the Maternity Hospital. Mononuclear cells were isolated from each sample using Ficoll-Plaque density gradient separation and were cryopreserved in 90\% fetal bovine serum (FBS)/10\% dimethylsulfoxide (DMSO). Cells were cultured in serumfree Iscove's Modified Dulbecco's Medium (IMDM) for $1 \mathrm{~h}$ before the addition of MCL compounds that were synthesized by the Chenyue lab at Nankai University, China. All treatments were performed in triplicate. Human leukemia cell lines KG1a, HL60, K562, HL60/ADR and K562/A02 were obtained from State Key Laboratory of Experimental Hematology (Tian Jin, China). Then these cells were cultured in 1640 medium, supplemented with $10 \%$ fetal bovine serum at $37^{\circ} \mathrm{C}, 5 \% \mathrm{CO}_{2}$.

\section{Mouse model of human AML}

Initially, NOD/SCID immune-deficient mice were irradiated with 280 centigray (cGy). Then, 6-10 h later, the mice received a tail vein injection of primary AML mononuclear cells in a final volume of $0.2 \mathrm{ml}$ PBS. Eight weeks after this cell transplantation, DMAMCL $(50 \mathrm{mg} / \mathrm{Kg}$ ) was administrated into the mice orally every other day. After 7 times the administration were stopped. The chemotherapy drug, adriamycin (ADR), were also administered every two days via tail vein at a dose of $1 \mathrm{mg} / \mathrm{Kg}$ for 4 times. Meanwhile, the survival was assessed and graphed by Kaplan-Meier plot. For immunofluorescence experiments, the mice received a single oral dose of $100 \mathrm{mg} / \mathrm{Kg}$ DMAMCL for $3 \mathrm{~h}$ and then were sacrificed.

\section{MTT cell proliferation assay}

Briefly, leukemia cells were seeded in 24 plates $\left(1 \times 10^{4}\right.$ cells/well $)$. Cells were treated with varying concentrations of MCL for $72 \mathrm{~h}$ and optical density (OD) values were determined at $570 \mathrm{~nm}$. $\mathrm{IC}_{50}$ values were calculated by using GraphPad Prism 5 (Graph Pad, San Diego, CA).

\section{Apoptosis assay}

After $18 \mathrm{~h}$ of treatment with MCL, normal and AML samples were stained with CD34-allophycocyanin (APC) and CD38-PE.cy7 antibodies for $30 \mathrm{~min}$. Cells were then washed with cold phosphate-buffered saline (PBS), resuspended in $100 \mu$ Lof binding buffer, and incubated with Annexin-V-fluorescein isothiocyanate (FITC) and propidium iodide (PI) for $15 \mathrm{~min}$. Samples were analyzed with a BD LSRII flow cytometer (BD Biosciences, New Jersey, America).

\section{Methylcellulose colony-forming cell assay}

Mononuclear cells from primary AML specimens or umbilical cord blood were cultured in serum-free IMDM for $18 \mathrm{~h}$ in the presence or absence of $5 \mu \mathrm{M}$ and $10 \mu \mathrm{M}$ MCL. Treated cells were plated at a concentration of $2 \times 10^{5}$ cells $/ \mathrm{ml}$ in Methocult H4434 in 24 plates. Colonies were scored after 7-12 d. All treatments were performed in triplicate.

\section{Immunofluorescence and confocal microscopy}

Cytocentrifuge preparations of bone marrow cells from AML mice were mounted onto glass slides and were left to dry overnight. Cells were then fixed with FAB Fluid for $1 \mathrm{~min}$ and were permeabilized with $0.5 \%$ Triton $\mathrm{X}-100$ for $12 \mathrm{~min}$. Cells were incubated in blocking buffer [10\% FBS $/ 0.1 \%$ Tween 20 in $1 \times$ PBS (pH 7.4)] and stained with rabbit polyclonal anti-p65 (C-20), anti-Nrf-2 (C-20) (Santa Cruz Biotechnology, Santa Cruz, CA), or anti-HO-1 (H-105; GeneTex Inc., San Antonio, TX) antibodies in $0.5 \%$ Triton $\mathrm{X}-100$ for $2 \mathrm{~h}$ at RT. Cells were then washed and stained with goat anti-rabbit Alexa Fluor 488 
(Invitrogen) secondary antibody for $30 \mathrm{~min}$. Finally, nuclei were stained with TO-PRO-3 for $10 \mathrm{~min}$ and images were obtained using a $40 \times$ objective.

\section{Electrophoretic mobility shift assay (EMSA)}

EMSA was performed as described. Briefly, $4 \mu \mathrm{g}$ of each nuclear extract was incubated with $1 \mu \mathrm{g}$ of poly-d(I-C) and 400 fmol biotinylated NF- $\mathrm{kB}$ probe in $1 \mathrm{X}$ binding buffer and $2.5 \%$ glycerol for $25 \mathrm{~min}$ at RT. Protein/DNA complexes were resolved on a native polyacrylamide gel in $0.5 \%$ Tris/borate/EDTA (TBE) buffer at $4^{\circ} \mathrm{C}$. After $2 \mathrm{~h}$, the complexes were transferred to a nylon membrane for $1 \mathrm{~h}$. Transferred DNA was crosslinked to the membrane and biotin-labeled DNA was detected by chemiluminescence.

\section{Quantitative RT-PCR}

Using SYBR Green reagents (Takara), mRNA expression was assessed. The primer sequences used included: HO-1 forward: 5'- TGT GGT ACA GGG AGG CCA TCA CC -3'; HO-1 reverse: 5'-CAG GAT TTG TCA GAG GCC CTG AAG G-3'; Nrf-2 forward: 5'- TCA CCA TCT CAG GGG CAG -3'; Nrf-2 reverse: 5'- CAA CAT ACT GAC ACT CCA ATG C-3'; NF-kB forward: 5'GGA GGC ATG TTC GGT AGT GG-3'; NF-kB reverse: 5'-CCC TGC GTT GGA TTT CGT G-3'. And GAPDH forward: 5'-AGGTCGGTGTGAACGGATTTG-3'; GAPDH reverse: 5'- GGGGTCGTTGATGGCAACA-3'. And the expression data was analyzed with Delta Ct.

\section{ROS production}

Cells treated with MCL were collected, washed with PBS, and incubated with $10 \mathrm{nM} \mathrm{2',7'-Dichlorofluorescin}$ diacetate (DCF-DA) (Beyotime, China) for $30 \mathrm{~min}$ at $37^{\circ} \mathrm{C}$. Samples were then washed twice with PBS and the intensity of FITC fluorescence was measured by flow cytometry (BD LSRII flow cytometer, BD Biosciences).

\section{Microarray transcriptional profiling}

KG1a cells were treated with $10 \mu \mathrm{M}$ MCL for $8 \mathrm{~h}$. Each sample was performed in triplicate. Cells were then frozen at $-20^{\circ} \mathrm{C}$ and a gene chip assay was performed by Shanghai Biotechnology Company (Shanghai, China). KG1a cells were collected for microarray analysis using Affymetrix Human Genome U133 plus 2.0 Array (Affymetrix). The expression data are available at National Center for Biotechnology Information Gene Expression Omnibus with accession number GSE76384.

\section{Western blotting assay}

KG1a cells and AML sample cells were treated with $10 \mu \mathrm{M}$ MCL for $8 \mathrm{~h}$ before protein lysis buffer was added to each set of cells for $30 \mathrm{~min}$ on ice. Then, centrifuged, and total protein concentrations were determined using BCA reagent. Each protein extract sample $(50 \mu \mathrm{g})$ was separated on a $12 \%$ gel, transferred to a nitrocellulose membrane, and incubated with primary antibodies raised against Bax, Bcl-2, PARP, caspase-3, caspase-9, P53, P-P53, XIAP, and GAPDH (Cell signaling technology, Boston, America) at $4^{\circ} \mathrm{C}$ overnight. The membranes were washed with PBS three times before being incubated with the appropriate anti-HRP secondary antibodies (Cell signaling technology, Boston, America) (1:2000) at RT. After $2 \mathrm{~h}$, bound antibodies were detected with an ECL-Plus Kit (Thermo Scientific, Rockford, America).

\section{ACKNOWLEDGMENTS AND FUNDING}

This work was funded by the National Basic Research Program of China (NO. 2016YFA0100602 and 2012CB966600), the National Natural Science Foundation of China (NSFC 81421002, 81430004, 81570100, and 81500086), and the Key Technologies R\&D Program of Tianjin (13RCGFSY19500).

\section{CONFLICTS OF INTEREST}

The authors declare no competing financial interests.

\section{REFERENCES}

1. Jamieson CH, Ailles LE, Dylla SJ, Muijtjens M, Jones C, Zehnder JL, Gotlib J, Li K, Manz MG, Keating A, Sawyers CL, Weissman IL. Granulocyte-macrophage progenitors as candidate leukemic stem cells in blastcrisis CML. The New England journal of medicine. 2004; 351:657-667.

2. Thomas D, Majeti R. Burning Fat Fuels Leukemic Stem Cell Heterogeneity. Cell stem cell. 2016; 19:1-2.

3. Ramdass B, Chowdhary A, Koka PS. Hematological malignancies: disease pathophysiology of leukemic stem cells. Journal of stem cells. 2013; 8:151-187.

4. Quek L, Otto GW, Garnett C, Lhermitte L, Karamitros D, Stoilova B, Lau IJ, Doondeea J, Usukhbayar B, Kennedy A, Metzner M, Goardon N, Ivey A, et al. Genetically distinct leukemic stem cells in human CD34-acute myeloid leukemia are arrested at a hemopoietic precursor-like stage. The Journal of experimental medicine. 2016.

5. Bjerkvig R, Tysnes BB, Aboody KS, Najbauer J, Terzis AJ. Opinion: the origin of the cancer stem cell: current controversies and new insights. Nature reviews Cancer. 2005; 5:899-904.

6. Borah A, Raveendran S, Rochani A, Maekawa T, Kumar DS. Targeting self-renewal pathways in cancer stem cells: clinical implications for cancer therapy. Oncogenesis. 2015; 4:e177. 
7. Crews LA, Jamieson CH. Selective elimination of leukemia stem cells: hitting a moving target. Cancer letters. 2013; 338:15-22.

8. $\mathrm{Hu} \mathrm{Y,} \mathrm{Li} \mathrm{S.} \mathrm{Survival} \mathrm{regulation} \mathrm{of} \mathrm{leukemia} \mathrm{stem} \mathrm{cells.}$ Cellular and molecular life sciences. 2016; 73:1039-1050.

9. Wang Y, Krivtsov AV, Sinha AU, North TE, Goessling W, Feng Z, Zon LI, Armstrong SA. The Wnt/beta-catenin pathway is required for the development of leukemia stem cells in AML. Science. 2010; 327:1650-1653.

10. Giambra V, Jenkins CE, Lam SH, Hoofd C, Belmonte M, Wang X, Gusscott S, Gracias D, Weng AP. Leukemia stem cells in T-ALL require active Hiflalpha and Wnt signaling. Blood. 2015; 125:3917-3927.

11. Park S, Chapuis N, Tamburini J, Bardet V, CornilletLefebvre P, Willems L, Green A, Mayeux P, Lacombe C, Bouscary D. Role of the PI3K/AKT and mTOR signaling pathways in acute myeloid leukemia. Haematologica. 2010; 95:819-828.

12. Martelli AM, Evangelisti C, Chiarini F, McCubrey JA. The phosphatidylinositol 3-kinase/Akt/mTOR signaling network as a therapeutic target in acute myelogenous leukemia patients. Oncotarget. 2010; 1:89-103. doi: 10.18632/ oncotarget.114.

13. Martelli AM, Evangelisti C, Chiarini F, Grimaldi C, Cappellini A, Ognibene A, McCubrey JA. The emerging role of the phosphatidylinositol 3-kinase/Akt/ mammalian target of rapamycin signaling network in normal myelopoiesis and leukemogenesis. Biochimica et biophysica acta. 2010; 1803:991-1002.

14. Guzman ML, Neering SJ, Upchurch D, Grimes B, Howard DS, Rizzieri DA, Luger SM, Jordan CT. Nuclear factor-kappaB is constitutively activated in primitive human acute myelogenous leukemia cells. Blood. 2001; 98:2301-2307.

15. Guzman ML, Upchurch D, Grimes B, Howard DS, Rizzieri DA, Luger SM, Phillips GL, Jordan CT. Expression of tumor-suppressor genes interferon regulatory factor 1 and death-associated protein kinase in primitive acute myelogenous leukemia cells. Blood. 2001; 97:2177-2179.

16. Papiez MA, Krzysciak W, Szade K, Bukowska-Strakova K, Kozakowska M, Hajduk K, Bystrowska B, Dulak J, Jozkowicz A. Curcumin enhances the cytogenotoxic effect of etoposide in leukemia cells through induction of reactive oxygen species. Drug Des Devel Ther. 2016; 10:557-570.

17. Testa U, Labbaye C, Castelli G, Pelosi E. Oxidative stress and hypoxia in normal and leukemic stem cells. Experimental hematology. 2016; 44:540-560.

18. Trachootham D, Alexandre J, Huang P. Targeting cancer cells by ROS-mediated mechanisms: a radical therapeutic approach? Nat Rev Drug Discov. 2009; 8:579-591.

19. Guzman ML, Rossi RM, Karnischky L, Li X, Peterson DR, Howard DS, Jordan CT. The sesquiterpene lactone parthenolide induces apoptosis of human acute myelogenous leukemia stem and progenitor cells. Blood. 2005; 105:4163-4169.

20. Guzman ML, Rossi RM, Neelakantan S, Li X, Corbett CA, Hassane DC, Becker MW, Bennett JM, Sullivan E,
Lachowicz JL, Vaughan A, Sweeney CJ, Matthews W, et al. An orally bioavailable parthenolide analog selectively eradicates acute myelogenous leukemia stem and progenitor cells. Blood. 2007; 110:4427-4435.

21. Jin P, Madieh S, Augsburger LL. The solution and solid state stability and excipient compatibility of parthenolide in feverfew. AAPS PharmSciTech. 2007; 8:E105.

22. Zhai JD, Li D, Long J, Zhang HL, Lin JP, Qiu CJ, Zhang Q, Chen Y. Biomimetic semisynthesis of arglabin from parthenolide. J Org Chem. 2012; 77:7103-7107.

23. Viennois E, Xiao B, Ayyadurai S, Wang L, Wang PG, Zhang Q, Chen Y, Merlin D. Micheliolide, a new sesquiterpene lactone that inhibits intestinal inflammation and colitis-associated cancer. Laboratory investigation; a journal of technical methods and pathology. 2014; 94:950-965.

24. Zhang Q, Lu Y, Ding Y, Zhai J, Ji Q, Ma W, Yang M, Fan H, Long J, Tong Z, Shi Y, Jia Y, Han B, et al. Guaianolide sesquiterpene lactones, a source to discover agents that selectively inhibit acute myelogenous leukemia stem and progenitor cells. Journal of medicinal chemistry. 2012; 55:8757-8769.

25. Xin H, Kong Y, Jiang X, Wang K, Qin X, Miao ZH, Zhu Y, Tan W. Multi-drug-resistant cells enriched from chronic myeloid leukemia cells by Doxorubicin possess tumorinitiating-cell properties. Journal of pharmacological sciences. 2013; 122:299-304.

26. Zhou J, Chng WJ. Identification and targeting leukemia stem cells: The path to the cure for acute myeloid leukemia. World journal of stem cells. 2014; 6:473-484.

27. Zeng H, Gu H, Chen C, Li M, Xia F, Xie L, Liu X, Zhang F, Tong X, Wang J, Yu Z, Zheng J. ChREBP promotes the differentiation of leukemia-initiating cells to inhibit leukemogenesis through the TXNIP/RUNX1 pathways. Oncotarget. 2016. doi: 10.18632/oncotarget.9520.

28. Zhang H, Mi JQ, Fang H, Wang Z, Wang C, Wu L, Zhang B, Minden M, Yang WT, Wang HW, Li JM, Xi XD, Chen SJ, et al. Preferential eradication of acute myelogenous leukemia stem cells by fenretinide. Proceedings of the National Academy of Sciences of the United States of America. 2013; 110:5606-5611.

29. Jin Y, Lu Z, Ding K, Li J, Du X, Chen C, Sun X, Wu Y, Zhou J, Pan J. Antineoplastic mechanisms of niclosamide in acute myelogenous leukemia stem cells: inactivation of the NF-kappaB pathway and generation of reactive oxygen species. Cancer research. 2010; 70:2516-2527.

30. Guzman ML, Swiderski CF, Howard DS, Grimes BA, Rossi RM, Szilvassy SJ, Jordan CT. Preferential induction of apoptosis for primary human leukemic stem cells. Proceedings of the National Academy of Sciences of the United States of America. 2002; 99:16220-16225.

31. Turillazzi E, Neri M, Cerretani D, Cantatore S, Frati P, Moltoni L, Busardo FP, Pomara C, Riezzo I, Fineschi V. Lipid peroxidation and apoptotic response in rat brain areas induced by long-term administration of nandrolone: the 
mutual crosstalk between ROS, NF-kB. Journal of cellular and molecular medicine. 2016; 20:601-612.

32. Riezzo I, Turillazzi E, Bello S, Cantatore S, Cerretani D, Di Paolo M, Fiaschi AI, Frati P, Neri M, Pedretti M, Fineschi V. Chronic nandrolone administration promotes oxidative stress, induction of pro-inflammatory cytokine and TNF-alpha mediated apoptosis in the kidneys of CD1 treated mice. Toxicology and applied pharmacology. 2014; 280:97-106.
33. Bubici C, Papa S, Dean K, Franzoso G. Mutual cross-talk between reactive oxygen species and nuclear factor-kappa B: molecular basis and biological significance. Oncogene. 2006; 25:6731-6748.

34. Li L, Huang T, Tian C, Xiao Y, Kou S, Zhou X, Liu S, Ye X, Li X. Thedefensive effect of phellodendrine against AAPHinduced oxidative stress throughregulating the AKT/NFkappaB pathway in zebrafish embryos. Life sciences. 2016. 